\title{
O imperialismo da moda europeia
}

\section{The imperialism of the european fashion}

\author{
Ana Luiza Nascimento Peres \\ Tecnóloga em Design de Moda pela Universidade Tecnológica Federal do Paraná (UTFPR) - analunperes@gmail.com - \\ http://orcid.org/0000-0003-4509-8630 \\ Marcio Roberto Ghizzo \\ Doutor em Geografia pela Universidade Estadual de Maringá (UEM). Professor da Universidade Tecnológica Federal \\ do Paraná (UTFPR) - marcioghizzo@gmail.com - http://orcid.org/0000-0002-0580-2358
}

\section{Resumo}

Os estudos de moda têm-se desenvolvido de forma mais intensa desde o último quarto do século passado e, principalmente, de modo interdisciplinar. Assim, analisá-la à luz da historicidade é uma possibilidade de compreensão de aspectos de seu desenvolvimento. O presente trabalho visa uma breve abordagem teórica relacionada à consolidação do imperialismo da moda europeia, algumas características de sua configuração no cenário atual e de sua influência sobre o modo de vestir do mundo todo. As principais capitais da moda possuem sua gênese firmada na história daquele continente e, na contemporaneidade, ainda exercem grande controle sobre o que é disseminado mundo afora. De uma forma geral, impõe-se imperativamente, manifestando conceitos e particularidades que a caracterizam de forma elegante e se torna objeto de consumo.

Palavras-chave: Moda. Internacionalização. Moda e globalização.

\begin{abstract}
Fashion studies have been developed more intensely since the last quarter of the last century, mainly in an interdisciplinary way. Therefore, analyzing it comprehending historicity is a possibility of understanding its development. The present paper aims at a brief theoretical approach related to the consolidation of European's fashion imperialism, as also some characteristics of its configuration in the current context and its influence on the way of dressing of the whole world. The main fashion capitals have their genesis established in the history of that continent and, in the contemporaneity, still maintain remarkable control over what is spread worldwide. In a general way, it imposes itself imperatively by manifesting concepts and particularities that characterize it as elegant and becoming an object of consumption.
\end{abstract}

Keywords: Fashion. Internationalization. Fashion and globalization.

Recebido em: 04/12/2017

Aceito em: 21/05/2019 


\section{INTRODUÇÃO}

A moda é um fenômeno que, indubitavelmente, tange as sociedades capitalistas. Fenômeno este tão complexo que se manifesta em diversas esferas que envolvem o indivíduo contemporâneo. O presente artigo é fruto de um Trabalho de Conclusão de Curso de Graduação da Universidade Tecnológica Federal do Paraná, campus Apucarana, defendido em 2016, e visa a análise da configuração da moda a partir da origem de sua centralização durante o reinado de Luís XIV, princípio da afirmação da Europa enquanto império, e o modo como esta influencia a moda mundial. A temática é explorada a fim de expor os aspectos que caracterizam a moda europeia como 'elegante', além de seu imperialismo global.

Para tanto, é necessário, primeiramente, contextualizar a moda no âmbito europeu, a fim da melhor compreensão de seu arranjo atual, das capitais de moda e da conseguinte disseminação de tendências mundo afora. Num segundo momento, considera-se a trama social, econômica e histórica da Europa, identificando particularidades de seu estilo contemporâneo que legitima seus conceitos e características, aludindo a elegância ao velho continente. Por fim, apresenta-se um breve panorama de aspectos que a globalização trouxe para a dinâmica das capitais da moda. Afinal, principalmente a partir do novo século, outras grandes cidades têm encontrado destaque no contexto da moda mundial sendo consideradas novas capitais da moda, embora a hegemonia daquele continente continue preponderante, principalmente no que tange à Paris.

Optou-se por desenvolver essa pesquisa por meio de estudos bibliográficos, tratando-se, portanto, de uma investigação de cunho teórico. Assim, no intuito de atingir o objetivo proposto, entende-se ser imprescindível contextualizar a origem da centralização da moda na Europa, bem como compreender a concentração das capitais da moda naquele continente. Afinal, por que a Europa é o continente, tradicionalmente, apresentado como responsável pelo lançamento das mais importantes coleções de moda? Há de se considerar, neste contexto, toda conjuntura que a faz berço da produção de moda e, na atualidade, mesmo com a ascensão de novos centros, a principal sede dos maiores palcos de lançamentos do mundo contemporâneo. 


\title{
2 CONSIDERAÇÕES SOBRE A CENTRALIZAÇÃO DA MODA NA EUROPA
}

A gênese da centralização da moda na Europa muito se relaciona ao princípio da convergência caracterizada pela existência de tendências, segundo Godart (2010). O autor menciona que, para Erner (2005), o conceito de tendência encontra-se nas focalizações de desejos. Entende-se, portanto, que as pessoas comungam um comportamento no qual as preferências caminham por uma linha-guia comum.

\begin{abstract}
No domínio da moda indumentária, o princípio da convergência é assegurado por um mecanismo de centralização que permite aos profissionais canalizar as evoluções que eles têm dificuldade de controlar. Isso significa que, se os estilos e designs criados e produzidos pelas casas de moda têm múltiplas origens, eles são selecionados e produzidos por um número reduzido tanto de empresas quanto de locais geográficos (GODART, 2010, p. 38).
\end{abstract}

Tal mecanismo originou-se no século XVII, durante o reinado de Luís XIV- o Rei Sol (16431715) - iniciado no decurso da Guerra dos Trinta Anos (1618-1648). Segundo Braga (2007), durante esse período nenhuma corte era capaz de ditar modos e modas, pois não havia homogeneidade nas vestimentas da Europa, as quais se diversificavam de acordo com a origem de suas populações.

Nas palavras de Palomino (2003), as capitais da moda localizadas no continente europeu, (Paris, Milão e Londres) formam, juntamente com Nova York, o chamado Planeta Fashion. Contudo, a mesma autora ratifica que, mesmo com a participação da capital norte americana, a hegemonia continua localizada no velho continente. Outros autores, como Godart (2010), Mendes e La Haye (2009) e Jacomet (2015), enfatizam que esta hegemonia encontra, na contemporaneidade, concorrência de novas capitais da moda inclusive em outros continentes, como América e Ásia, as quais emergiram da própria Europa durante a globalização. Contudo, salienta-se o foco desse trabalho no continente europeu, por este motivo o privilegia na discussão.

Essa centralização do Planeta Fashion na Europa antecedeu a moda tal como apresenta-se na atualidade, com gênese na França como resultado da sua consolidação enquanto potência continental e pela dupla afirmação, de Versalhes e Paris, como centros políticos, culturais e econômicos franceses, ainda no século XVII.

Após a Guerra dos Trinta Anos, a França tornou-se a primeira potência da Europa, onde Luís XIV centralizava o poder estatal. Essa centralização não se limitou apenas ao Estado, mas foi adiante: “A 'monarquia absoluta' de Luís XIV gera uma centralização sem precedentes nas tendências indumentárias europeias" (GODART, 2010, p. 39). O autor assinala que o objetivo de 
tudo isso ultrapassava apenas desviar a atenção dos nobres, uma vez que, até então, as influências derivavam de diferentes polos, situados em países como Espanha e Países Baixos. O intuito era, também, estabelecer o poder da França e de seu Estado: “A partir de 1660, a corte de Versalhes começou, de fato, a se impor para o restante da Europa com os novos padrões sociais, criando boas maneiras, etiquetas, modos e, principalmente, moda" (BRAGA, 2007, p. 49).

Assim, no século XVIII, a rainha Maria Antonieta (1755-1793) permitiu o desenvolvimento da moda emergida, até então, por meio de fatores externos ao próprio ambiente, fossem eles imposições ou escolhas das classes mais abastadas. Nesse período, a moda veio a tornar-se autônoma:

[...] a moda aparece antes de tudo como o agente por excelência da espiral individualista e da consolidação das sociedades liberais. E é na roupa, em especial, que os homens assumem e dão visibilidade à sua individualidade e sociabilidade perante o grupo em que se inserem (LIPOVETSKY, 1989, p. 13).

A centralização teve por objetivo concentrar a produção de têxteis na França e, com efeito, propiciar aos alfaiates e modistas, a dominação por completo dos concorrentes europeus. Em suma, a centralização da moda, proposta por Luís XIV, permitiu seu desenvolvimento em um ambiente específico que a controlava e a encaminhava consoante ao mais conveniente para o Estado.

Como consequência deste processo, foi na França que, em meados do século XIX, surgiu a alta-costura, tendo como protagonista Charles Worth, a qual criava roupas para novos-ricos e pequenos-burgueses. Assim, "sua origem, claro, é Paris... Nascia o conceito de alta-costura (haute couture), e o estilista tinha agora um status de criador supremo, diferentemente das costureiras e alfaiates" (PALOMINO, 2003, p. 12).

Atualmente, essa centralização assume novas formas adequadas ao contexto que envolve a moda e ao cenário de mudança muito mais rápida e constante. Porém, ainda sustentando o objetivo de focalizar evoluções e a hegemonia do velho continente. Desta maneira, "a centralização da moda é assegurada pelas casas de moda, que criam os estilos e designs que são vistos nos desfiles das principais cidades do mundo" (GODART, 2010, p. 41).

Essa centralização proporciona à Europa manter hegemonia no lançamento de tendências, disseminadas pelas casas de modas localizadas, principalmente, nas tradicionais capitais da moda. Na mesma linha de raciocínio, Breward (2003) destaca que o número limitado de capitais da moda, 
mesmo crescente, continua referindo-se a Nova York, Londres, Milão e Paris, conforme também defendido por Palomino (2003) e exposto anteriormente, sendo a última considerada o maior polo de criação fashion mundial. Em contrapartida, a partir do século XXI, novas capitais da moda surgiram, tais quais Los Angeles (Estados Unidos), São Paulo (Brasil), Tóquio (Japão) e Antuérpia (Bélgica), entre outras (GODART, 2010).

Nesse sentido, tratando-se do maior polo de criação fashion mundial, importa relativizar que "Paris impôs-se muito cedo devido ao fato, por um lado, da dominação política da França na Europa no século XVIII e, por outro, pela centralização de diferentes tipos de poder no âmago da aglomeração parisiense" (GODART, 2010, p. 57).

Ratificando este processo, Lipovetsky (1989) sinaliza, em vários momentos, a Europa como um continente em destaque ao se tratar de moda, haja vista que desde o início do segundo milênio encontrou posição de destaque no que tange à fabricação e uso de indumentárias.

De acordo com Palomino (2003), Londres se estabeleceu, tal qual Paris, como uma capital de moda quando ainda havia uma relativa divisão de trabalho entre estas duas capitais (século XIX), onde a primeira influenciava principalmente a moda feminina e a segunda a masculina, além da juventude e culturas de rua. Assim, para as duas outras capitais da moda, Milão e Nova York, a concretização deste título culminou em um período mais tardio, portanto, de menor expressão.

No que condiz à Nova York, ao fim da Segunda Guerra mundial, encontrou relevância pelo prêt-à-porter e o sportswear. Nas palavras de Braga (2007, p. 86), "a indústria do prêt-à-porter tornou-se cada vez mais significativa, especialmente por influência norte-americana, e o sportswear se popularizava cada vez mais".

Quanto à Milão, sua história é mais recente, e

Antes da Segunda Guerra Mundial, também a Itália fazia o jogo da cópia dos franceses. O
país dirigiu seu foco para o mercado americano no final dos anos 40, apoiado por uma mão-
de-obra superqualificada e uma aristocracia ambiciosa, pronta para reerguer-se das agruras
da guerra. Giovanni Battista Giorgini fez o primeiro desfile para compradores e imprensa
internacionais em Florença, em 1951, e esse é considerado um marco na moderna moda
italiana. A relevância da Itália foi reforçada nos anos 50 , como estilos de vida; ao longo dos
60 e 70 , apoiou-se também numa manufatura excelente e na qualidade de seus materiais -
bem como em seu design (PALOMINO, 2003, p. 25).

Portanto, foi no fim da década de 1970 que Milão emergiu como uma capital da moda devido ao status que possuía como centro industrial italiano. 
Estabelecidas como capitais, essas quatro cidades asseguram suas hegemonias até a atualidade, favorecidas pelos valores de tradição e história agregados ao longo dos anos, mesmo com o surgimento de novos polos. Valores sustentados em uma conjuntura geográfica de ordem imperial, a qual diz respeito à três das capitais. Ao passo que Paris, Milão e Londres situam-se na Europa, uma assimilação de poder voltado à estas cidades, culmina na formação de um continente na qualidade de império no âmbito da moda.

É em razão de nossa disposição para admirar, e consequentemente imitar, os ricos e os notáveis que lhes é possível estabelecer, ou conduzir, o que chamamos de moda. A roupa que vestem é a roupa em moda; a linguagem que usam em sua conversa é o estilo em moda; o porte e as maneiras que exibem são o comportamento em moda (SMITH, 1759, p. 64).

Assim, percebe-se que o prestígio da moda europeia possui também caráter histórico. Visto os aspectos que se impõem na contemporaneidade, efetivam-se as influências europeias de design sobre outros lugares e criadores fora desse continente.

Ademais, é válido ressaltar que esse imperialismo contemporâneo da moda europeia se transpõe também à diversos designers não europeus e advindos de outras cidades que tendem a se firmar como novas capitais da moda. Esses, lá se estabeleceram e fizeram fama. Neste caso, tem-se como exemplo os afamados criadores japoneses Kenzo, Rei Kawakubo, Issey Miyake e Yohji Yamamoto que, segundo Braga (2007), chegaram em Paris em 1980.

Uma composição de aspectos, aliada ao contexto histórico de consolidação europeia enquanto império de moda, auxilia no entendimento das razões pelas quais a Europa conquistou, e persiste atestando, sua posição de relevância no mundo da moda. Lipovetsky (1989) defende que há uma nova relação com a herança, uma valorização inédita do passado histórico: o desejo pósmoderno de reconciliar criação e permanência, moda e intemporalidade.

O "poder histórico", associado ao velho continente, é reafirmado quando analisados os dois maiores conglomerados de moda e luxo e suas origens. São eles: Kering, antiga Pinault Printemps Redoute (PPR) e Louis Vuitton Moët Hennessy (LVMH), ambos originários da França, onde as marcas de moda fundidas pelo mesmo grupo são, em sua maioria, de origem europeia. Para expor esse cenário de fusão, cita-se marcas como: Gucci, Bottega Veneta, Saint Laurent, e Balenciaga, membros Kering; e Louis Vuitton, Loewe, Berluti, Fendi, Céline, Christian Dior e Givenchy, membros LVMH. Algumas mais recentes e outras centenárias carregam tradição no mercado, e atestam que 
para além de estarem impondo-se a longo prazo, ainda são elevadas a patamares de idolatria e tidas como referências mundiais.

[...] veem-se aprovados os "sem idade", a herança, as grandes marcas históricas. [...] A época deu meia-volta: eis-nos tomados pelas paixões ao patrimonial e ao que não está sujeito a sair de moda, por toda parte são celebradas as tradições, a continuidade, os "lugares de memória" (LIPOVETSKY, 1989, p. 17).

Portanto, designers notáveis, de renome e com estimada tradição e princípios característicos das grandes casas da Europa são, como nunca, absorvidos por outras marcas ao redor do mundo, e passam a disseminar variáveis de determinada moda aos consumidores, ainda que estes estejam longe do epicentro da sua gênese. Associa-se este fato ao que Svendsen (2010, p. 44) cita em sua obra:

Spencer encontra as origens da moda em emblemas e outras coisas que simbolizam status, e salienta que essas características distintivas tendem a se espalhar, sendo adotadas por mais pessoas que aquelas que, estritamente falando, têm direito a elas.

Ou seja, as tendências emergidas a partir do continente europeu não se restringem mais àquele espaço, mas tangem o mundo em totalidade, com particularidades configuradas com o 'cenário imperial' retratado. Além disso, é comum designers de capitais da moda de outros continentes ou países recorrerem às capitais europeias, principalmente Paris, para arguirem o reconhecimento esperado por suas criações, como mencionado anteriormente.

\subsection{CARACTERIZAÇÃO E DISSEMINAÇÃO DA MODA EUROPEIA}

Similar à centralização das tendências indumentárias europeias, ocorrida na França no século XVII, séculos depois, o velho continente continua a impactar na configuração da disseminação de tendências de moda. Nesse caso, importa considerar que, "usualmente, designase sob o nome de tendência qualquer fenômeno de polarização pelo qual um mesmo objeto - no sentido mais amplo da palavra - seduz simultaneamente um grande número de pessoas" (ERNER, 2005, p. 104).

Segundo Braga (2007), a década de 1970 configurou-se num novo cenário no qual criou-se na França um comitê de estilo cuja finalidade era direcionar as propostas de moda. "Foi assim criada, em meados dos anos 1970, uma feira de moda têxtil a ser exibida em Paris com o nome de Première Vision (Primeira Visão), na qual as indústrias têxteis exporiam seus lançamentos" (BRAGA, 
2007, p. 92). Atualmente, a feira de lançamentos ainda existe e está presente também em outros polos do mundo, tais como Nova York e Istambul, apresentando as referências direcionadoras de moda.

Outra via difusora também iniciada na França e condutora da moda naquele período, e até hoje, são os chamados bureaux de style. Segundo Rech (2002), são cadernos de tendências que oferecem conteúdo a fim de melhor atender o mercado, os quais apresentam diretrizes que refletem seus anseios:

Cor, tecidos planos e de malharia, aviamentos e formas, componentes essenciais da moda e principais veículos das modificações, impostas semestralmente, são providos em cadernos específicos, a cada patamar industrial, em datas rigorosas, para garantir uma ação coordenada de todos, com o objetivo de atender, sempre melhor, os desejos dos consumidores (RECH, 2002, p. 39).

Atualmente, o mercado conta com ferramentas de pesquisa desse gênero como o pioneiro Promostyl (1966) e Peclers (1970) (apud Tungate, 2005) ambos de origem francesa, e sites de pesquisa de tendências como o Worth Global Style Network (WGSN).

Ademais, coligindo grandes casas de moda, a Europa é tradicionalmente um notório berço disseminador de tendências. Muitas destas traduzidas em produtos nas fashion weeks e projetadas amplamente por meio de veículos de comunicação, culminados nos outros continentes. Rech e Perito (2009) expõem que uma tendência surge na moda quando uma pessoa capacitada a cria e a impulsiona. No que diz respeito a esta criação, as autoras afirmam que o sociólogo Erner (2005) enuncia, como habilitados, os estilistas e alguns atores e cantores, por exemplo.

Devido ao poder de influência de que gozam esses personagens, é justificado que se presenteie ou empreste a eles os artigos que as marcas pretendem promover. Quando uma celebridade é vista portando esse artigo uma epidemia começa, a mídia de moda divulga e milhares de pessoas imitam (RECH; PERITO, 2009, p. 5).

O enquadramento atual da mídia, em um contexto de extrema velocidade na veiculação de conteúdo, configura um comportamento de difusão de moda mais volátil e hipermidiático, seduzindo os indivíduos ao seu universo de efemeridade.

Ao antigo universo em surdina sucedem a hipermidiatização das grandes casas, a "estrelização" dos chefs cozinheiros e dos grandes designers, a proliferação das obras sobre os criadores, os produtos finos e a história dos mais "belos objetos" (LIPOVETSKY, 1989, p. 16). 
Associado à dispersão de moda para o mundo a partir de uma centralização inicial, podem ser veiculadas particularidades que dizem sobre a sua gênese. A caracterização da moda de uma região sob o aspecto de outra externa é articulada tanto pela mídia como pela história, atingindo uma dimensão espaço-temporal.

Quando o vestuário de determinado país é caracterizado, a sua assimilação é comumente referenciada ao estilo prevalecente, e este “(...) é um conjunto de influências diversas relativamente estáveis" (GODART, 2010, p. 72), ou seja, um conjunto de pormenores do vestuário que coadjuvam na aparência geral. Nas palavras de Kalil (2008, p. 13), "o estilo entra e se impõe. Faz suas escolhas, elege alguns itens, dispensa outros. Seleciona, separa, organiza, até ficar com o que combina com seus traços".

Para o presente trabalho é relevante considerar que a caracterização da moda europeia abrange a identificação de especificidades no âmbito dos países das capitas de moda, com enfoque na principal, Paris. Portanto, para caracterizar o estilo europeu, é apropriado delinear o que Inès de La Fressange (2011), ícone da elegância na França, expõe em "A Parisiense", sua obra sobre como vestir-se à maneira dessa cidade, conhecida como notória e influenciadora de moda.

Figura 01 - Itens clássicos de vestuário: trench coat e jeans

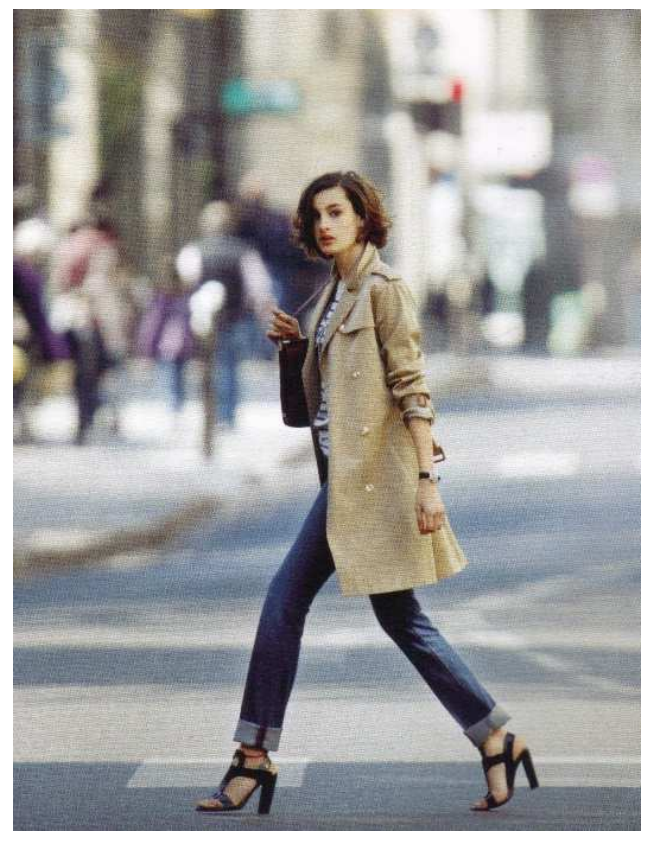

Fonte: La Fressange (2011, p. 27). 
Um dos focos iniciais do livro de La Fressange é sobre os itens clássicos de vestuário, os quais fazem parte do estilo de Paris, a saber, blazer, trench coat, suéter, jaqueta de couro, os triviais conhecidos jeans e camiseta, e o célebre "pretinho básico".

Por meio dessas peças de roupas, La Fressange (2011) orienta como sofisticar o básico, surpreender com combinações incomuns, e como ser sutilmente sensual, algumas características de comportamento da moda parisiense. Também o faz com relação à contrastes entre peças de origem prestigiosa combinadas ao street culture, assim como joias em conjunto com bijuterias e o uso de clássicos. Porém, em arranjos que assegurem um visual não convencional, conforme mostra a Figura 2, são outros itens levantados e que aludem à mulher da capital francesa.

Figura 02 - Combinação de camiseta, blazer e bijuteria

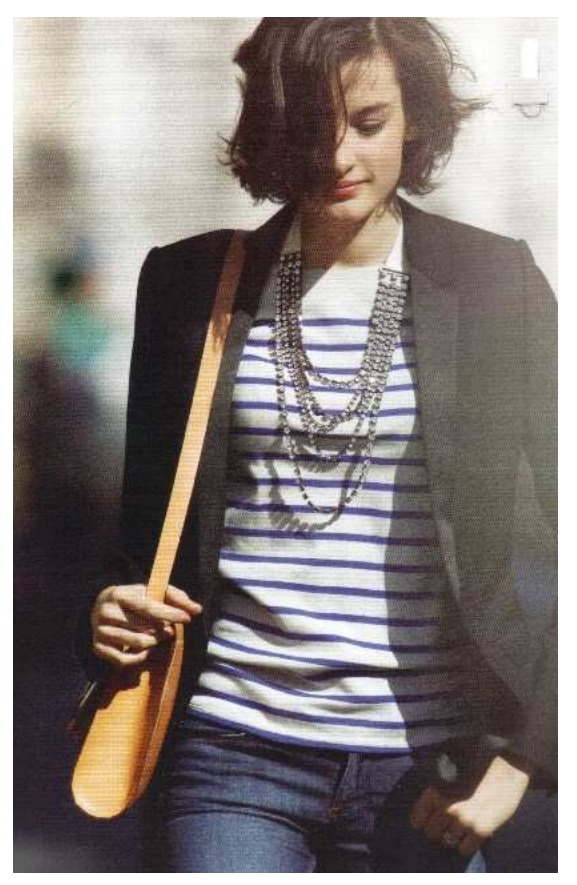

Fonte: La Fressange (2011, p. 49).

Quando analisados os apontamentos da autora, logo é possível relacioná-los ao fator herança. Segundo Duarte (2012), no século XX, quando Paris era chamada de "capital do mundo", Chanel, célebre estilista, já propunha alguns dos arranjos mencionados por Inès de La Fressange. $\mathrm{Na}$ época, Chanel foi pioneira em propor a mistura de joias com fantasias. Nas palavras de Duarte 
(2012, p. 202), "passava a mensagem que a maneira de combinar os elementos e não o valor dos mesmos era o fundamental para uma pessoa mostrar que tinha estilo".

A estilista também combinava pesos e texturas inusitados, como o jérsei e a seda. "A socialite Suzanne Orlandi foi a primeira mulher a usar um original de Chanel - um vestido de veludo preto com uma gola de pétalas brancas" (KARBO, 2010, p. 66), uma referência para a moda "pois marcou a criação do "eterno pretinho básico", que até os dias de hoje faz parte do guarda roupa da maioria das mulheres" (DUARTE, 2012, p. 198).

No que tange a caracterização das roupas por meio de cores e tecidos, a moda inglesa assegura posição de relevância. Segundo Lurie (1997), no século XIX a roupa da mulher revelava cores, muitos adereços e uma profusão de panos e ornamentos combinados. Entretanto, a autora relata que, ao longo dos últimos cinquenta anos, os trajes descontraídos e os de trabalho das mulheres passaram a obedecer ao referido "princípio da camuflagem". Muito influenciada pela arquitetura e pelo clima de Londres, as roupas urbanas "são, na maioria das vezes, em cores que ecoam as nuanças da pedra, cimento, fuligem, céus nublados e calçadas úmidas: preto, branco, azul-marinho e as tonalidades escuras de cinza" (LURIE, 1997, p. 115).

Figura 03 - Variante do "pretinho básico"

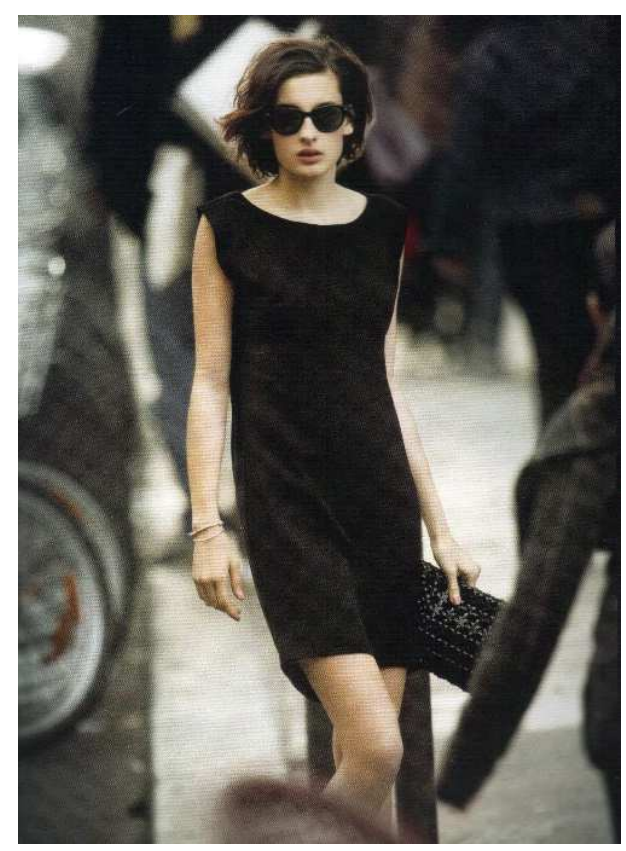

Fonte: La Fressange (2011, p. 33). 
A autora segue descrevendo o traje inglês, e expõe que os tons baixos e sombrios são coloridos por meio de detalhes: uma gravata para os homens, por exemplo, ou uma única peça estampada como realce na composição do coordenado. Na esfera dos tecidos, os "lisos, sem adornos, são os preferidos; se há algum padrão, este tende a ser retangular. As listras estreitas são especialmente populares" (LURIE, 1997, p. 116). De acordo com a autora, o vestuário inglês acaba por fundir a figura humana à paisagem urbana, suas formas e padrões.

Acerca da moda italiana, é destacado o caráter da alta qualidade.

Características típicas da moda italiana pós-guerra originaram-se das relações entre o design de roupas de luxo e a indústria da confecção. O prêt-à-porter italiano representou a industrialização das roupas, mas com conteúdo altamente criativo e simbólico (CRANE; MORA, 2008, p. 160).

Segundo as autoras supracitadas, a modernização da indústria italiana possibilitou um prêt-à-porter com muito estilo e a preços razoáveis, em que os designers criaram uma estética muito influenciada pelo gênero das roupas masculinas.

Figura 1 - Padrão listrado do vestido consoante ao cenário urbano

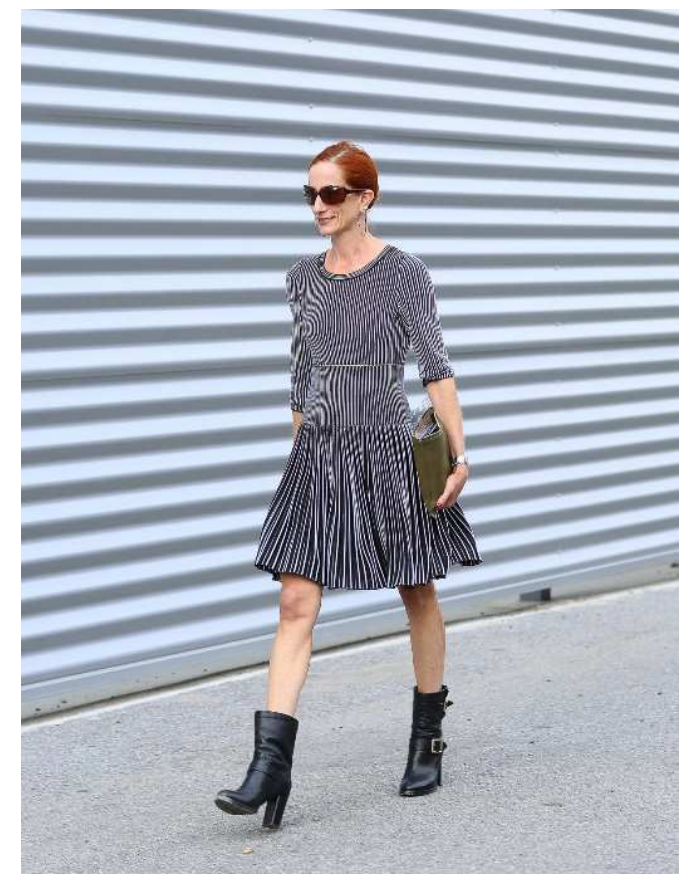

Fonte: Lee Oliveira (2016). 
Crane e Mora (2008, p. 162) ponderam que a descentralização da produção de moda italiana, baseada na subcontratação, possibilita às grandes empresas atender às constantes mudanças de tendências ocorridas no mercado internacional com produtos de alta qualidade:

[...] essa extrema fragmentação contribui para o alto nível de criatividade do sistema italiano de moda, uma vez que, nessas pequenas empresas locais, produtoras de materiais e outros produtos, trabalham artesãos muito criativos e trabalhadores altamente qualificados.

Em síntese, a moda italiana é configurada em um cenário no qual prevalece a valorização do trabalho de artesãos com ênfase na alta qualidade, exclusividade, originalidade e aspectos de bens culturais geradores de caráter simbólico aos consumidores. Nas palavras de Crane e Mora (2008, p. 168), "todos os agentes (do designer ao consumidor) compartilham uma forte apreciação por elegância, luxo e pelos aspectos estéticos das peças de roupas".

Figura 05 - Detalhes de um look da marca italiana Fendi

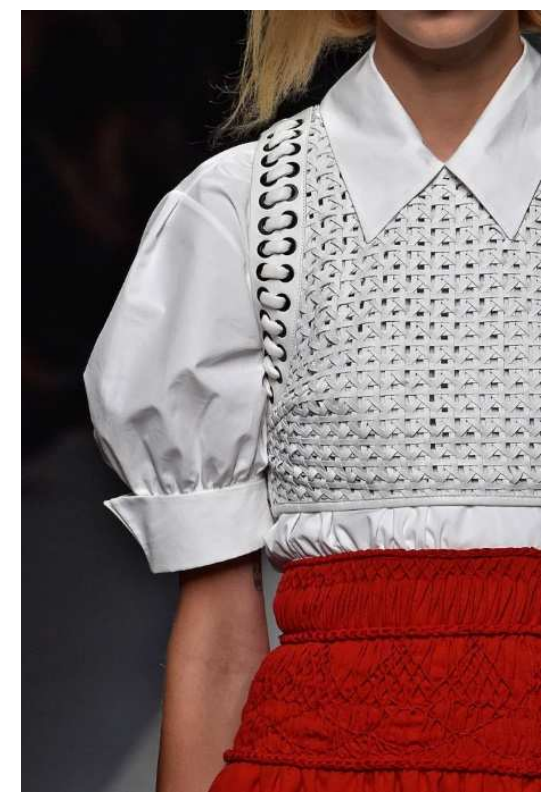

Fonte: FFW (2015).

A partir das perspectivas evidenciadas, é incontestável o fato de que "a moda ganhou algumas identidades com relação aos países de sua origem" (BRAGA, 2007, p. 87). O estilo da maneira de vestir de cada país assume caracterizações por meio dos pormenores que o integram e que acabam por defini-lo. Dessa maneira, conclui-se que, para caracterizar o estilo europeu em um âmbito geral, implica admitir a ele atributos como a valorização de peças clássicas de vestuário, a 
combinação ousada e não óbvia de elementos, a sofisticação, as cores sóbrias, os padrões geométricos, a primazia estética, a criatividade, a perícia profissional, a alta qualidade e o uso de materiais que garantem um vestuário de excelência. Esses pormenores juntos possibilitam à moda europeia ostentar o título a ela atribuído: moda elegante de um continente imperialista.

\subsection{O IMPERIALISMO DA MODA EUROPEIA E A GLOBALIZAÇÃO}

$\mathrm{Na}$ contemporaneidade, principalmente com o advento da globalização, a dinâmica das capitais da moda tem se mostrado um processo que ganha relativa intensidade. Afinal, "o desenvolvimento e a difusão, desde 1960, das novas tecnologias de comunicação ampliam ainda mais as noções de tempo-espaço social [...] e uma maior percepção de simultaneidade de ter a experiência de novos lugares e novas sensações" (DULCl, 2015, p. 84).

No mesmo sentido, Jacomet (2016, n.p.) atesta que "esta mundialização da indústria da moda dá lugar à uma concorrência global intensa", de modo a aparecerecem novos concorrentes na Ásia e na Turquia, além de outras na própria Europa e até mesmo nas Américas, merecedoras de atenção.

Assim, no que tange à moda, entende-se que embora permaneça a hegemonia do continente europeu, não se deve negligenciar a eclosão de novos polos produtores e, consequentemente, novas capitais de moda, mesmo, por hora, de menor magnitude.

Godart (2010) destina um capítulo de seu livro para tratar das capitais da moda europeias e, neste, um subcapítulo destinado à Paris e as novas capitais emergentes. Porém, o autor enfatiza a hegemonia do velho continente ainda assegurada, pois até mesmo os calendários fashion mundiais são organizados de forma a permitir, aos maiores nomes da moda, participarem dos grandes eventos nas quatro principais capitais da moda mundial, das quais três são europeias. Porém, não há a mesma consideração com a organização de eventos nas demais cidades mundiais emergentes, onde acontecem eventos de menor expressividade.

Para Godart (2010), assim como Mendes e La Haye (2009) e Jacomet (2016), Paris ainda detêm o título de capital da moda mundial. A cidade foi o berço da moda contemporânea e, embora haja uma concorrência cada vez mais acirrada entre metrópoles mundiais para atrair mentes criativas, Paris ainda o realiza de forma espontânea e natural. 
Contudo, reconhece-se que Paris, a exemplo das demais capitais enfatizadas neste trabalho, deve com o tempo ceder espaço para as concorrentes. Nesse sentido, para Steele $(2005$, p. 56) “Paris não é mais 'a' capital da moda, mas uma das capitais da moda, um primus inter pares (primeiro entre iguais), que deve se conciliar com influências vindas do mundo inteiro, não somente de Nova York, Londres ou Milão, mas também de Tóquio ou Antuérpia".

Nessa conjuntura, torna-se primaz reconhecer o papel das novas capitais da moda em termos mundiais. Afinal, com a globalização, não se deve tratar de uma capital da moda, mas de várias cidades que exercem influência na moda global. No entanto, ainda existe uma importante hierarquia entre estas cidades.

De forma geral, Paris continua detendo o título sob o ponto de vista financeiro e midiático, principalmente quanto à alta costura. No que diz respeito ao poder das marcas, essa hegemonia tem-se, com os anos, mostrado menos evidente, e marcas francesas como Louis Vuitton e Chanel, sempre muito poderosas, tem encontrado certa concorrência, como as italianas Gucci e Prada, ou as americanas Calvin Klein e Ralph Lauren. Quanto a criatividade e novos talentos, para Godart (2010, p. 57), Londres e Nova York estão no escopo, "ela [Paris] perdeu sua coroa de capital única, mas permanece na frente do pelotão".

Os autores supracitados compreendem que há uma complexidade sobre as capitais da moda. De forma geral, há concordância que Paris e Londres são as principais capitais da moda e que, principalmente a primeira, detém a hegemonia nos campos político, histórico, artístico e econômico. Mas esta centralidade não é mais plena.

Ressalta-se nestes primeiros anos de século XXI, que várias cidades abrigaram influentes semanas da moda, como Los Angeles e São Paulo. Outros países, como Nova Zelândia e Irã também tem encontrado relativo e crescente destaque neste tipo de evento. Outros polos com ênfase na formação de novos talentos tem sido Tóquio, no Japão e Antuérpia, na Bélgica (Mendes; La Haye, 2009). Porém, essas cidades, assim como outros polos mencionados, têm dificuldades para manter seus criadores de moda em suas origens. Estes, sempre que podem, migram para, principalmente, Paris, onde buscam seus reconhecimentos profissionais.

Além dos polos citados, Copenhague, Estocolmo, Berlim, Miami entre outros, também apresentam relativa importância estilista; enquanto Barcelona, Madri, Moscou, Bombaim, Hong 
Kong e Xangai exercem maior importância de mercado, permanecendo aquém nos quesitos midiáticos, criativos e simbólicos.

Essa dinâmica das capitais da moda e novos polos da moda é complexa e foge do escopo deste trabalho, o qual objetiva tratar do imperialismo da moda europeia, algumas de suas características e a consequente influência exercida na moda mundo afora. Porém, entende-se a pertinência e magnitude desta discussão.

Assim, reitera-se que estes novos polos são "uma fonte de crescimento para as empresas europeias no momento em que o consumo de mercados domésticos diminui" (JACOMET, 2016, s.p.). Porém, embora as estruturas e dimensões das capitais da moda possuem diferentes níveis de ação social, ainda é limitado o número de capitais da moda que atraem o essencial midiático e definem a moda.

Em nível local, afirma Godart (2010), realmente há outros e novos protagonistas de destaque, com influência exercida na interação local-global, mas que ainda não conseguem a mesma magnitude como as quatro capitais à frente dessa corrida pelo poder.

Os novos protagonistas, embora ainda modestos já preocupam e ameaçam aqueles que estão no escopo, principalmente os países asiáticos, como China e Índia que tem aumentado seu poder. Contudo, por hora, "Paris, Milão, Nova York e Londres continuam a ser as principais capitais de moda do mundo, para as quais os estilistas continuam a migrar para fazer nome" (MENDES; LA HAYE, 2009, p. 280).

\section{CONSIDERAÇÕES FINAIS}

A moda enquanto fenômeno social é fator notável. A maneira como manifesta-se e envolve o indivíduo contemporâneo é diferente em cada sociedade. Porém, com um importante aspecto em comum: influências externas.

A temática exposta nesse artigo visou tratar algumas particularidades da moda europeia que repercutem no mundo todo e, consequentemente, no Brasil. Polo da maior concentração de capitais de moda, inclusive aquelas fora do escopo da hierarquia global, o imperialismo estabelecido pelo continente europeu advém de contextos políticos, históricos, tramas sociais e econômicas que o fazem berço da produção fashion, bem como epicentro da disseminação de 
tendências pelo mundo. Favorecida pelos valores sustentados em tradição e história, a Europa afirma posição de prestígio quanto à caracterização de moda elegante.

Com gênese no século XVII, esse imperialismo permanece nos dias atuais e a hegemonia do velho continente se faz presente na indumentária utilizada mundo afora. Além disso, o gosto pelos produtos de estética europeia perdurará enquanto este continente continuar a afirmar-se como um império de moda.

Contudo, na contemporaneidade, principalmente após o advento da globalização, a hegemonia da moda europeia encontrou algumas ameaças, principalmente de outras cidades europeias e asiáticas. Portanto, a dinâmica das capitais da moda merece atenção e, numa dimensão espaço-tempo, pode haver alterações no cenário mundial. Contudo, por hora, as tradicionais capitais europeias continuam à frente desta corrida com tendência a se tornar cada vez mais acirrada.

Dessa forma, entende-se que o estudo realizado permitiu verificar e entender esta influência da moda europeia sob o mundo todo, desde sua gênese até a atualidade, pautada na criação de roupas que possuem na elegância a sua grande peculiaridade. Também proporcionou discutir, embora de forma breve, a dinâmica das capitais da moda que tende, com o passar do tempo e com as transformações pertinentes à globalização, trazer novidades acerca desta competitividade entre cidades.

\section{REFERÊNCIAS}

BRAGA, João. História da moda: uma narrativa. São Paulo: Anhembi Morumbi, 2007.

BREWARD, Christopher. Fashion. Oxford: Oxford University Press, 2003.

CRANE, Diana; MORA, Emanuela. Diferenças entre os sistemas de moda de cada país: o caso da Itália. IARA: Revista de Moda, Cultura e Arte, São Paulo, v.1, n.1, p. 142-173, abr/ago. 2008. Disponível em: http://www1.sp.senac.br/hotsites/blogs/revistaiara/wpcontent/uploads/2015/01/06_IARA_Crane_versao-final.pdf. Acesso em: 19 jul. 2019.

DUARTE, Sonia Carmem Teló. Chanel: uma análise semiótica. Moda Palavra, Florianópolis, v. 5, n. 10, p. 187-210, jul-dez. 2012. Disponível em:

http://www.revistas.udesc.br/index.php/modapalavra/article/view/7758. Acesso em: 19 jul. 2019. 
DULCI, Luciana Crivellari. Globalização, moda e a cultura do consumismo. Dobras, [s.I.] v. 8, n. 17, maio 2015. Disponível em: https://dobras.emnuvens.com.br/dobras/article/view/13. Acesso em: 19 jul. 2019.

ERNER, Guillaume. Vítimas da moda?: como a criamos, por que a seguimos. São Paulo: Senac São Paulo, 2005.

FFW. [Fendi]. 24 set. 2015. 1 fotografia. Disponível em: http://ffw.com.br/desfiles/milao/verao2016-rtw/fendi/1540320/detalhes/4/. Acesso em: 19 jul. 2019.

GODART, Frédéric. Sociologia da moda. São Paulo: Senac São Paulo, 2010.

JACOMET, Dominique. A mundialização da indústria da moda. In: CANTISTA, Isabel (coord.). Espaços de moda geográficos, físicos e virtuais. Coimbra: Conjuntura Actual, 2016.

KARBO, Karen. O evangelho de Coco Chanel: lições de vida da mulher mais elegante do mundo. São Paulo: Seoman, 2010.

LA FRESSANGE, Inès de. A parisiense: o guia de estilo de Ines de la Fressange com Sophie Gachet. Rio de Janeiro: Intrínseca, 2011.

OLIVEIRA, Lee. [These 10 street style looks will inspire your summer wardrobe part 2]. 8 abr. 2016. 1 fotografia. Disponível em: http://leeoliveira.com/these-10-street-style-looks-will-inspire-yoursummer-wardrobe-part-2-by-lee-oliveira-2/. Acesso em: 19 jul. 2019.

LIPOVETSKY, Gilles. O império do efêmero. São Paulo: Companhia das Letras, 1989.

LURIE, Alison. A linguagem das roupas. Rio de Janeiro: Rocco, 1997.

MENDES, Valerie; LA HAYE, Amy de. A moda do século XX. 2. ed. São Paulo: Martins Fontes, 2009.

PALOMINO, Erika. A moda. São Paulo: Publifolha, 2003.

RECH, Sandra Regina. Moda: por um fio de qualidade. Florianópolis: UDESC, 2002.

RECH, Sandra Regina; PERITO, Renata Z. Sobre tendências de moda e sua difusão. Florianópolis, v. 4, n. 6, p. 637-643, 2009. Disponível em:

http://revistas.udesc.br/index.php/dapesquisa/article/view/14239/9312. Acesso em: 19 jul. 2019.

SMITH, Adam. The theory of moral sentiments. London: Guttenberg, 1759.

SVENDSEN, Lars. Moda: uma filosofia. Rio de Janeiro: Zahar, 2010.

TUNGATE, Mark. Fashion brands: branding style from Armani to Zara. London: Kogan Page, 2005. 